\title{
CARACTERIZAÇÃO DA TEMPERATURA DO AR NO ESTADO DE GOIÁS E NO DISTRITO FEDERAL
}

\author{
DIAS CARDOSO, Murilo Raphael - murilo.cardoso@me.com \\ IESA / UFG - Universidade Federal de Goiás \\ MARCUZZO, Francisco Fernando Noronha - francisco.marcuzzo@cprm.gov.br \\ SGB / CPRM \\ BARROS, Juliana Ramalho - juliana.ufg@superig.com.br \\ IESA / UFG - Universidade Federal de Goiás
}

\begin{abstract}
RESUMO
O Estudo da temperatura do ar é de suma importância no que diz respeito ao planejamento das atividades humanas, sejam elas de grande ou pequena escala e impacto. Sendo assim, esse estudo propôs a executar uma caracterização espacial da temperatura no Estado de Goiás e Distrito Federal. Para isso, foram utilizados dados de temperatura de 47 estações meteorológicas dentro e nas proximidades da área de estudo. Essas estações e seus respectivos dados foram transformados em vetor do tipo ponto e trabalhados em um ambiente de SIG. Na espacialização dos dados por toda a área de estudos foi utilizado o método de interpolação Topo to Raster. Constatou-se que, no Estado de Goiás e no Distrito Federal, o mês mais quente do ano é o de outubro e os mais amenos são julho e junho com amplitude térmica, entre o mês mais quente e o mais frio, de $4,5^{\circ} \mathrm{C}$. A região mais quente apresentada foi a do Noroeste goiano, local de menor altitude, e as regiões de menor temperatura foram entre os municípios de Goiânia e Anápolis, ao redor de Brasília e Sudoeste do Estado de Goiás, regiões de maior altitude, comprovando a influência do relevo na variação da temperatura. Constatou-se, também a influência do uso e ocupação do solo na variação da temperatura no Estado de Goiás e Distrito Federal.
\end{abstract}

Palavras-chave: Geoprocessamento, Topo to Raster, Climatologia.

CHARACTERIZATION OF AIR TEMPERATURE IN THE STATE OF GOIÁS AND THE FEDERAL DISTRICT

ABSTRACT

The study of air temperature is of paramount importance with regard to the planning of human activities, with large or small scale and impact. Thus, this study aimed to perform a spatial characterization of temperature in the state of Goiás and Federal District. For this, it was used temperature data from 47 meteorological stations in and around the study area. These stations and their data were converted to vector point and worked in a GIS environment. In spatial distribution of data across the study area was used interpolation method Top Raster. It was found that, in the State of Goiás and the Federal District, the hottest month of the year is October and are milder in June and July with temperature range between the warmest and the coldest of $4.5^{\circ} \mathrm{C}$. The hottest region was presented to the Northwest Goias, local lower altitude and lower temperature regions were among the municipalities of Goiânia and Anápolis around Brasilia and southwest of the Goiás State, higher altitudes, showing the influence of relief under the conditions presented by this climate variable. It was found also the influence of the use and occupation of land in the temperature variation in the state of Goiás and Federal District.

Keywords: GIS, Topo to Raster, Climatology

\section{INTRODUÇÃO}

O estudo da temperatura do ar é de grande relevância para o entendimento dos demais fenômenos climatológicos de uma região, além de auxiliar no planejamento e gerenciamento do uso e ocupação do solo. Ademais, os elementos do clima estão diretamente relacionados com a formação da fitofisionomia de determinada região, além de influenciar nas práticas do diaa-dia das pessoas. Contudo, a região em que estão inseridos o Estado de 
Goiás e o Distrito Federal tem grande carência de estudos do clima comparadas às regiões sul-sudeste e norte do Brasil. Por esse viés, esse estudo se torna importante para servir como material base para outros estudos da temperatura nas regiões do Estado de Goiás e Distrito Federal, bem como ser consultada para informações sobre o clima dessas regiões em atividades compatíveis com a escala proposta no estudo.

O clima é o principal agente natural modificador da paisagem. Sendo a paisagem uma das categorias de estudo da Geografia, a importância desse tipo de estudo para essa ciência se torna imprescindível. A paisagem geográfica se apresenta como uma unidade fisionômica de cunho natural ou/e cultural associada a uma determinada área do espaço geográfico, e analisadas morfologicamente, observando-se a integração das formas entre si e o caráter orgânico, ou quase orgânico, delas. (CORRÊA e ROZENDAHL, 1998, p.9). De forma mais direta, entrando no campo das dualidades fundamentais da ciência geográfica (GOMEZ, 1996, p.112), a Climatologia é considerada um dos ramos da Geografia Física (PÉDELABORDE, 1970, p.95-96), e por esse viés, a importância de seu estudo se torna ainda mais evidente dentro dessa ciência.

Como principais variáveis do clima, nesse processo de transformação da paisagem geográfica, podemos citar a precipitação e a temperatura. Existem alguns fatores regionais que podem influenciar tanto na dinâmica da temperatura quanto da precipitação. Em relação à temperatura, a latitude pode ser considerada o principal fator determinante de sua variação nas mais diferentes regiões do globo. Isso porque a posição latitudinal está diretamente relacionada com a quantidade de radiação recebida. Há também o fator da proximidade com corpos d'água, quanto maior a quantidade e proximidade desses corpos d'água, a temperatura tende a ser amenizada. As grandes diferenças de temperatura entre os trópicos, local onde estão inseridos o Estado de Goiás e o Distrito Federal, são usualmente devido ao efeito da variação da altitude. A temperatura do ar diminui, em média, cerca de $0,6^{\circ} \mathrm{C}$ a cada 100 metros de altura (AYOADE, 1983, p.7-8).

Segundo Nimer (1989), a região Centro-Oeste do Brasil tem clima caracterizado por invernos secos e verões chuvosos. O tempo seco no meio do ano juliano (inverno) tem sua origem na estabilidade gerada pela influência do anticiclone subtropical do Atlântico Sul e de pequenas dorsais que se formam sobre a parte continental sul americana. O período de chuva está associado ao deslocamento para sul da Zona de Convergência Intertropical (ZCI, também conhecida como CIT), acompanhando a marcha aparente do sol em direção ao Trópico de Capricórnio. Sobre a porção central da América do Sul a CIT avança mais para sul do que nas regiões costeiras gerando instabilidade em todo o Brasil central nos meses de verão. Em função da influência da massa de ar tropical marítima e equatorial, as temperaturas são 
elevadas durante todo o ano. No inverno, quando a CIT está deslocada para norte, a região apresenta baixa ou nenhuma precipitação.

Segundo o estudo de Da Silva et al. (2008), o clima predominante na região do Estado de Goiás e do Distrito Federal é o Tropical sazonal, de inverno seco. A temperatura média anual fica em torno de $22,0-23,0^{\circ} \mathrm{C}$, sendo que as médias mensais apresentam pequena estacionalidade. As máximas absolutas mensais não variam muito ao longo dos meses do ano, podendo chegar a mais de $40,0^{\circ} \mathrm{C}$. Já as mínimas absolutas mensais variam bastante, atingindo valores próximos ou até abaixo de zero, nos meses de maio, junho e julho.

O objetivo deste trabalho foi executar a caracterização da temperatura no Estado de Goiás e Distrito Federal utilizando a espacialização dados pontuais de temperatura de 47 estações meteorológicas localizadas na área de estudo e em suas proximidades. Essas estações e seus respectivos dados foram transformados em vetor do tipo ponto e trabalhados em um ambiente de SIG no estudo.

\section{MATERIAL E MÉTODOS}

\section{Uso e Cobertura do Solo e Demografia}

A área de estudo deste trabalho está localizada no Centro-Oeste do Brasil, o Estado de Goiás e o Distrito Federal. A área total do Estado de Goiás é de $340086,7 \mathrm{~km}^{2}$, enquanto o Distrito Federal ocupa uma área que totaliza $5801,9 \mathrm{~km}^{2}$. Segundo o Censo 2010, o Estado de Goiás tem uma população total de 5.849.105 milhões de habitantes distribuídos por 243 municípios, sendo Goiânia, a capital do Estado, a mais populosa com 1.256.514 milhões de habitantes, $21,5 \%$ do total da população do Estado. Já o Distrito Federal, contabiliza 2.469.489 milhões de habitantes e, por se tratar de um distrito, não é dividido em municípios (IBGE, 2011).

Como pode ser observado na Figura 1, a cobertura do solo no Estado de Goiás e no Distrito Federal, é representada por praticamente dois tipos de uso antrópico, pecuária e agricultura, e a maioria dos remanescentes da vegetação pioneira se encontram no Nordeste goiano e no Norte do Distrito Federal. Toda a área do Distrito Federal está localizada dentro da região do bioma Cerrado. Contudo, o Estado de Goiás tem quase todo o seu território inserido dentro do bioma Cerrado, exceto 3,5\% de sua área total, localizada no Sudeste do Estado, que está dentro do domínio do bioma Mata Atlântica. 


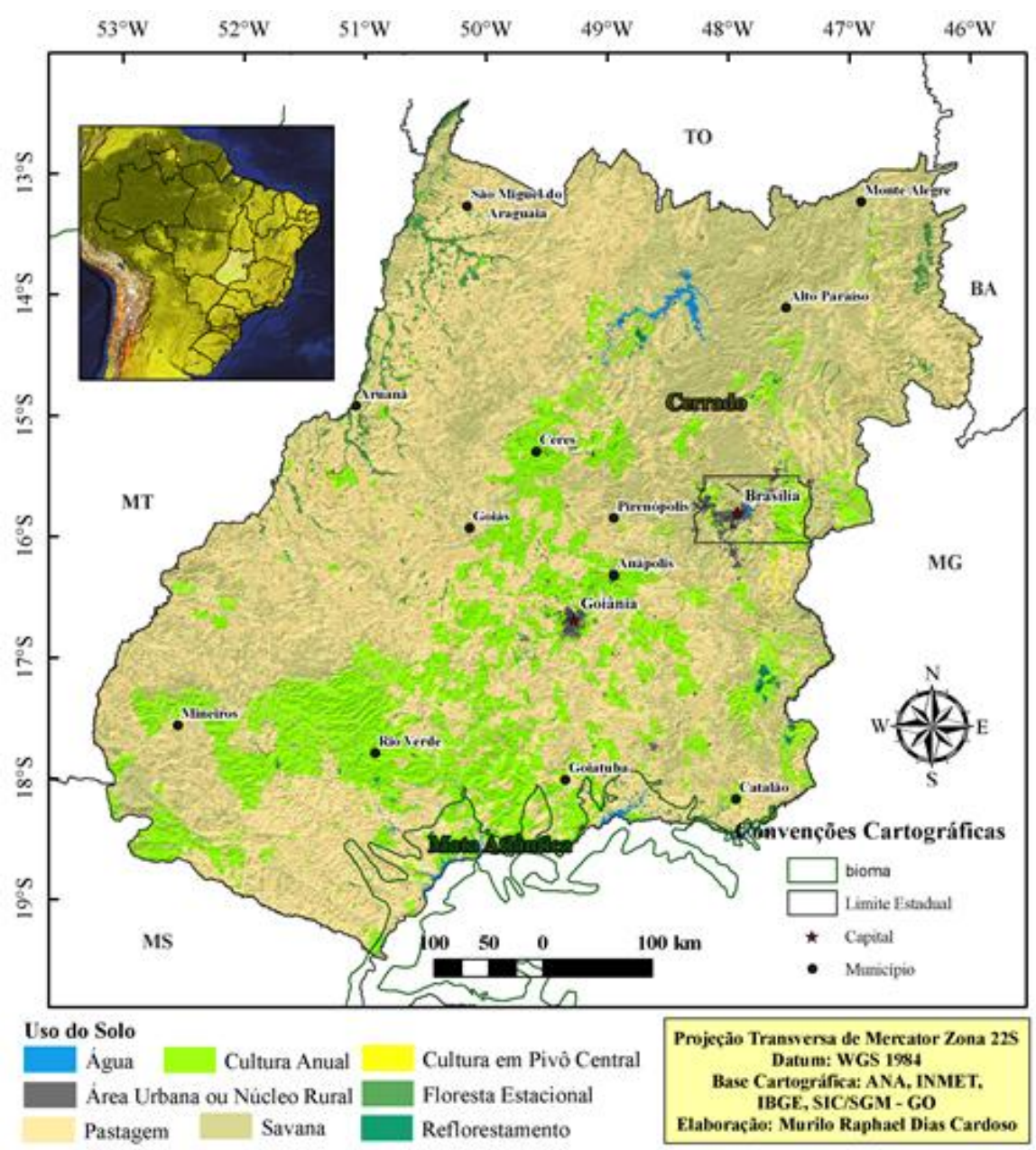

Figura 1. Uso e Cobertura do Solo no Estado de Goiás e Distrito Federal

\section{Altimetria da Área de Estudos}

Como mencionado anteriormente, um importante fator que molda o clima de uma determinada região é a altitude. No Estado de Goiás e no Distrito Federal não existem grandes altitudes que sirvam, por assim dizer, de barreiras naturais às massas de ar que passem por essa região. A região mais baixa dessa área, Estado de Goiás e Distrito Federal, está localizada no Noroeste goiano, com altitudes mínimas chegando a $186 \mathrm{~m}$, próximas ao curso do Rio Araguaia. As maiores altitudes podem ser observadas em uma faixa meridional que percorre pela região do Nordeste Goiano às proximidades da capital federal. O ponto mais alto atinge $1670 \mathrm{~m}$ e está localizado na Chapada dos Veadeiros, mais precisamente no município de Alto Paraíso (Figura 2) (NASA, 2002). 


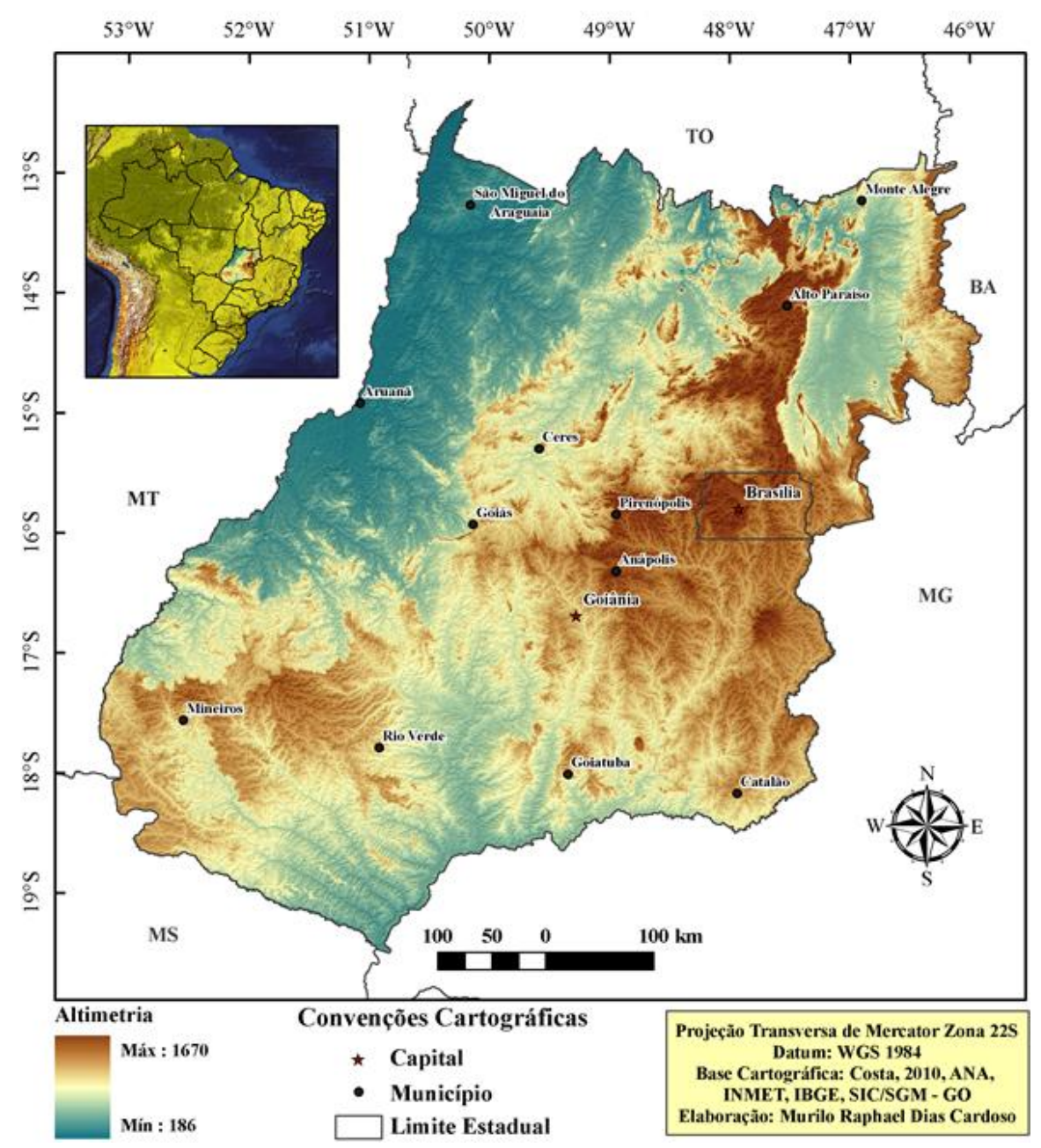

Figura 2. Altimetria no Estado de Goiás e Distrito Federal

\section{Estações Meteorológicas e Pluviométricas}

Na caracterização da temperatura do Estado de Goiás e Distrito Federal, foram utilizadas 47 estações do INMET (Figura 3). Todos os dados das estações são disponibilizados no sistema Hidroweb, mantido pela ANA. Os dados utilizados no estudo são referentes a 10 anos, de 1989 à 1998. Esse intervalo de tempo foi escolhido por apresentar menos falhas em relação a coleta dos dados. Para os dados mensais, foi feita média simples da média diária de todos os dias do mês. Os valores anuais de temperatura foram estipulados fazendo a média dos meses e para a precipitação a soma dos mesmos. Os dados referentes as estações utilizadas no estudo foram organizados de forma a ter para a temperatura a média mensal e anua. Logo, os valores utilizados na confecção dos mapas foram a média dos 10 anos. Com esses valores estipulados para cada ponto, que representa cada estação, 
era preciso utilizar um método de interpolação para extrapolar os dados para todas as regiões da área de estudos, como será visto no item a seguir. Para isso foi utilizado o método Topo to Raster que foi aplicado utilizando um programa em ambiente SIG.

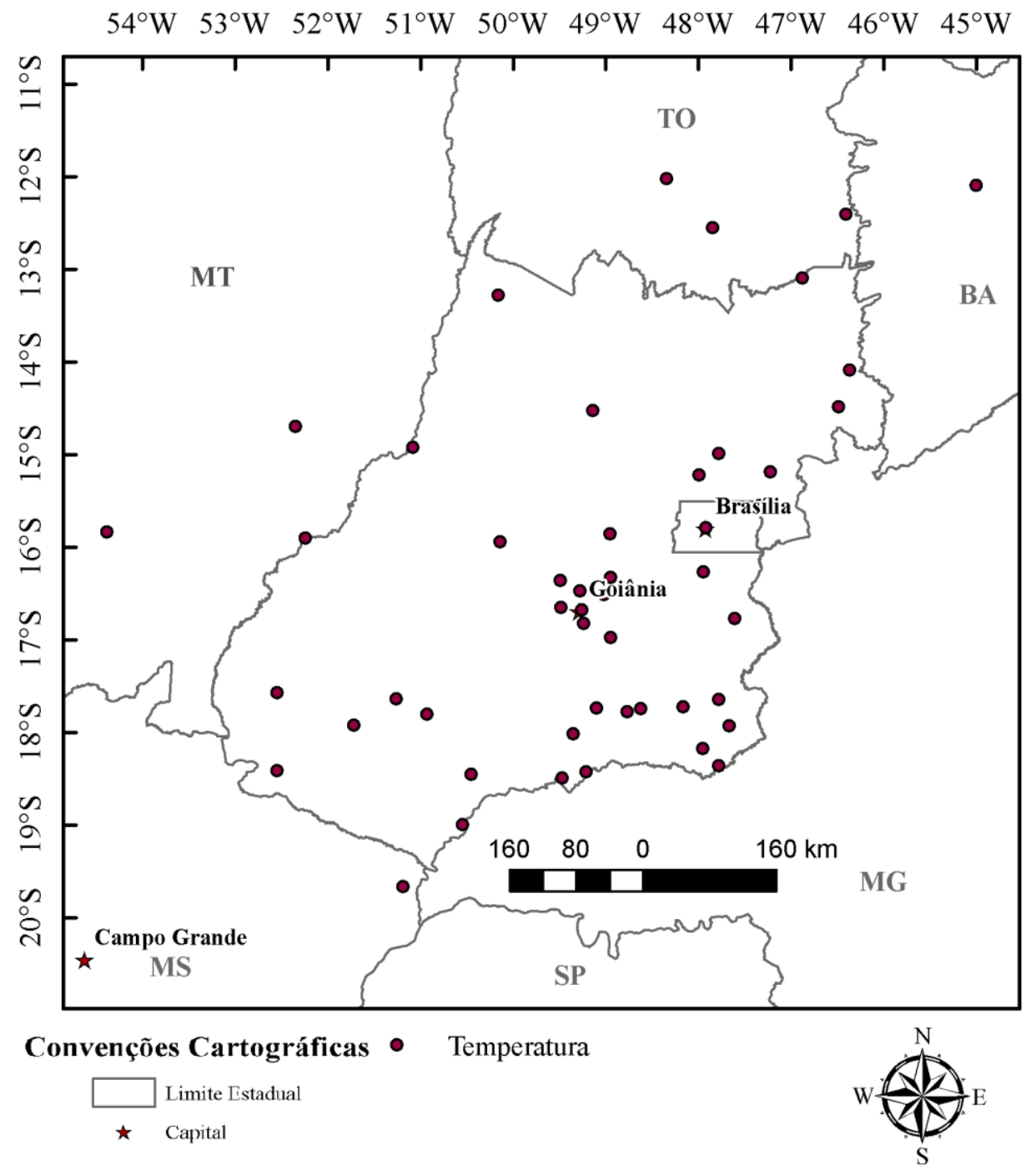

Figura 3. Estações utilizadas no estudo (Fonte: INMET)

Interpolação matemática pelo método Topo to Raster

A função Topo to Raster é um método de interpolação baseado no programa ANUDEM desenvolvido por Hutschinson, que foi especificamente feito para a criação de MDE hidrologicamente corretos, contudo alguns estudos o indicam como o melhor para a interpolação de dados climatológicos (MARCUZZO et al., 2011, p.709). 
O programa interpola os dados de clima em uma grade regular, de modo interativo, gerando grades sucessivamente menores, minimizando a soma de uma de penalização de rugosidade (roughness penalty) e a soma dos quadrados dos resíduos (diferenças das elevações medidas e calculadas pela função).

Cada elevação em um determinado local é dada por:

$z_{i}=f\left(x_{i}, y_{i}\right)+w_{i} \varepsilon_{i}$

em que, $f(x, y)$ é a função de interpolação, definida por uma função B-spline, cada wi é uma constante positiva que representa o erro de discretização do ponto i e cada ci é uma amostra de uma variável aleatória de média zero e desvio padrão igual a um.

Assumindo que cada ponto está localizado aleatoriamente dentro da célula do modelo, a constante wi é definida por:

$w_{i}=\frac{h s_{i}}{\sqrt{12}}$

$\sum_{i-1}^{n}\left[\left(z_{1-f\left(x_{i} y_{i}\right)}\right) \div w_{i}\right]^{2}+\lambda J(f)$

em que, h é o espaçamento da grade; si é a medida de inclinação da célula da grade associada com o ponto ( $x i, y i)$. A função $f(x, y)$ é então estimada resolvendo uma aproximação na grade regular via método das diferenças finitas que minimiza a somatória. A constante wi varia com cada iteração, em uma característica adaptativa local (locally adaptive feature), já que a cada iteração do programa um novo valor de inclinação (si) é disponibilizado para cada célula da grade conforme o método iterativo avança.

O programa utiliza o método multi-grid simples para minimizar a equação em resoluções cada vez melhores, começando de uma grade inicial larga até uma grade que tenha resolução definida pelo usuário, respeitando restrições que garantem uma estrutura de drenagem conectada.

\section{RESULtAdOS E discusSÃo}

\section{Temperatura Média Mensal}

$\mathrm{Na}$ análise da temperatura média mensal (Figura 4) para a área de estudo em questão pode se observar uma variação de até $4,5^{\circ} \mathrm{C}$ entre o mês mais frio e o mês mais quente. Os valores mais baixos de temperatura foram encontrados nos meses de junho e julho, com média de temperatura de $20,8^{\circ} \mathrm{C}$. Enquanto o mês mais quente foi o mês de outubro, com média de temperatura de $25,3^{\circ} \mathrm{C}$. Em ordem decrescente, as temperaturas médias do ar no Estado de Goiás e no Distrito Federal estão distribuídas da seguinte forma: outubro $\left(25,3^{\circ} \mathrm{C}\right)$, dezembro $\left(24,6^{\circ} \mathrm{C}\right)$, novembro $\left(24,5^{\circ} \mathrm{C}\right)$, janeiro e 
março $\left(24,2^{\circ} \mathrm{C}\right)$, fevereiro e setembro $\left(24,1^{\circ} \mathrm{C}\right)$, abril $\left(23,7^{\circ} \mathrm{C}\right)$, agosto $\left(22,7^{\circ} \mathrm{C}\right)$, maio $\left(22,1^{\circ} \mathrm{C}\right)$ e junho e julho $\left(20,8^{\circ} \mathrm{C}\right)$.

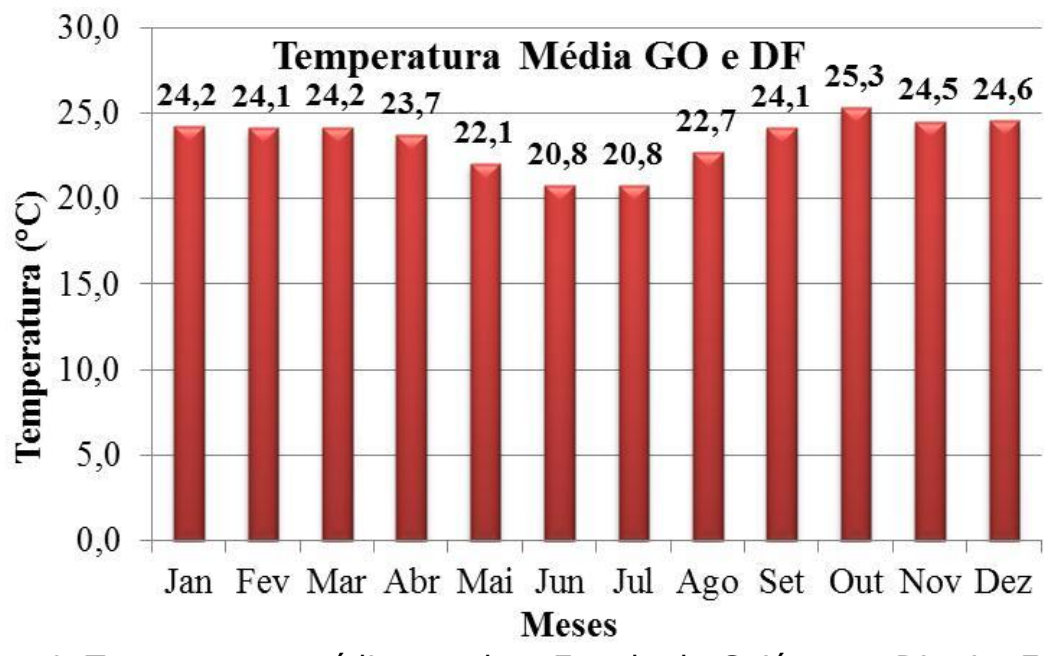

Figura 4. Temperatura média anual no Estado de Goiás e no Distrito Federal

Como podemos observar na Figura 5 , as temperaturas mais elevadas no mês de janeiro se apresentam na região Noroeste, com média de $26,0^{\circ} \mathrm{C}$ a $27,0^{\circ} \mathrm{C}$ e as menores temperaturas estão presentes em uma pequena área entre os municípios de Anápolis e Goiânia e no Nordeste Goiano. No mês de janeiro as menores temperaturas foram de $21,0^{\circ} \mathrm{C}$ a $22,0^{\circ} \mathrm{C}$. Para o mês de fevereiro, os valores mais altos de temperatura se apresentaram na região Noroeste com estimativas entre $25,0^{\circ} \mathrm{C}$ e $26,0^{\circ} \mathrm{C}$. Enquanto os menores valores de temperatura se apresentaram, novamente seguindo a tendência do mês de janeiro, na região próxima aos municípios de Anápolis e Goiânia, com valores entre $20,0^{\circ} \mathrm{C}$ e $21,0^{\circ} \mathrm{C}$. Durante o mês de março os maiores valores de temperatura ocorreram no Noroeste Goiano com a média de temperatura mensal apresentando valores entre $26,0^{\circ} \mathrm{C}$ e $27,0^{\circ} \mathrm{C}$. Os menores valores de temperatura média para o mês de março se repetiram as localizações dos meses de janeiro e fevereiro, e ficaram espacializados entre os municípios de Goiânia e Anápolis $\left(20,0^{\circ} \mathrm{C}\right.$ a $\left.21,0^{\circ} \mathrm{C}\right)$ e no Nordeste Goiano $\left(21,0^{\circ} \mathrm{C}\right.$ a $22,0^{\circ} \mathrm{C}$ ). No mês de abril as configurações apresentadas pelos maiores e menores valores de temperatura média mensal começam a dispersar para outras regiões do Estado de Goiás, bem como no Distrito Federal.

Os valores mais altos de temperatura se apresentaram novamente na região Noroeste do Estado de Goiás, contudo, em uma faixa oeste-leste nessa região, observou-se valores entre $27,0^{\circ} \mathrm{C}$ e $28,0^{\circ} \mathrm{C}$, aproximadamente $5,0^{\circ} \mathrm{C}$ acima da média geral do mês de abril. Os altos valores de temperatura da região Noroeste, apresentados nesses primeiros quatro meses analisados, são um dos indícios que explicam um dos porquês de essa região ser ocupada amplamente por pecuária (Figura 1). Apesar de esse quadrimestre apresentar valores de precipitação média que possibilitariam o plantio, como será visto Ano 8 - Vol. 11 - JUL/DEZ 2012 
mais a frente, esses altos valores de temperatura se tornam o empecilho para a maioria das culturas cultivadas no Estado de Goiás. Os valores mais baixos novamente foram encontrados entre os municípios de Goiânia e Anápolis $\left(19,0^{\circ} \mathrm{C}\right.$ a $\left.20,0^{\circ} \mathrm{C}\right)$, porém as baixas temperaturas, que já se apresentavam no Nordeste, se estenderam em uma faixa mais ao Sul, cobrindo uma região de Nordeste a Leste. Outra região que demonstrou menores valores de temperatura média foi a Sudoeste com valores entre $20^{\circ} \mathrm{C}$ e $21^{\circ} \mathrm{C}$. Percebese, contudo, que por abril ser o último mês do período úmido, que os valores máximos e mínimos começam a variar espacialmente nessa época do ano. No mês de maio, primeiro mês do período seco, as temperaturas mais baixas se alocam definitivamente na região Nordeste, próximo a fronteira de Goiás com a Bahia e Minas Gerais, no Sudoeste Goiano e na região de Brasília, onde os valores vão de $19,0^{\circ} \mathrm{C}$ a $20,0^{\circ} \mathrm{C}$, e na região entre os municípios de Goiânia e Anápolis com valores médios estipulados entre $18,0^{\circ} \mathrm{C}$ e $20,0^{\circ} \mathrm{C}$. A região Noroeste se mantém como a mais quente do Estado de Goiás com valores médios de temperatura entre $24,0^{\circ} \mathrm{C}$ e $25,0^{\circ} \mathrm{C}$. Durante o mês de junho os valores mais baixos de temperatura se estendem da região Nordeste cobrindo o Estado de Goiás e o Distrito Federal de Nordeste a Sudeste com valores de $18,0^{\circ} \mathrm{C}$ a $20,0^{\circ} \mathrm{C}$ e nas regiões entre os municípios de Goiânia e Anápolis e no Sudoeste Goiano onde apresentaram valores médios de temperatura entre $15,0^{\circ} \mathrm{C}$ e $18,0^{\circ} \mathrm{C}$. A região Noroeste se manteve como a mais quente do Estado de Goiás no mês de junho com valores médios de temperatura entre $23,0^{\circ} \mathrm{C}$ e $25,0^{\circ} \mathrm{C}$. 


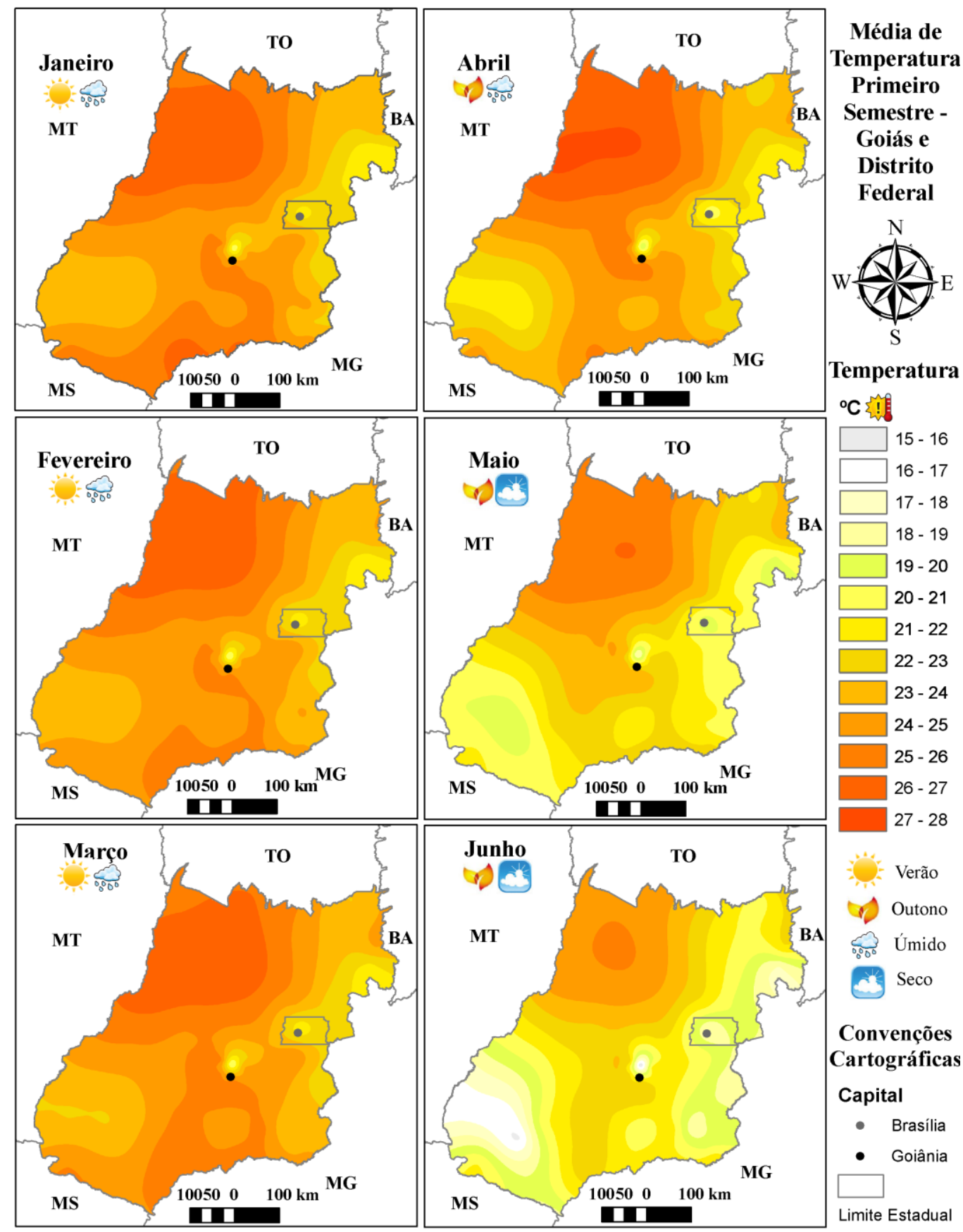

Figura 5. Distribuição espacial da temperatura média no primeiro semestre no Estado de Goiás e no Distrito Federal

No mês de julho, que juntamente ao mês de junho, foram o meses com a média geral de temperatura mais baixa, as menores temperaturas se espacializaram de maneira similar ao mês anterior. As temperaturas mais baixas se mantiveram entre $15,0^{\circ} \mathrm{C}$ e $18,0^{\circ} \mathrm{C}$ ocupando as regiões Sudoeste, 
entre os municípios de Goiânia e Anápolis e no eixo Nordeste-Sudeste (Figura 6).

As temperaturas mais altas também se mantiveram em região similar ao mês anterior, contudo apresentaram valores mais baixos, entre $22,0^{\circ} \mathrm{C}$ e $24,0^{\circ} \mathrm{C}$. No mês de agosto as temperaturas voltaram a aumentar, mas as espacialidades de máximas e mínimas se mantiveram similares ao ocorrido no mês anterior. Nas regiões de temperatura mais baixa os valores variaram entre $17,0^{\circ} \mathrm{C}$ e $20,0^{\circ} \mathrm{C}$, enquanto nas regiões de temperatura mais elevado os valores estiveram entre $23,0^{\circ} \mathrm{C}$ e $25,0^{\circ} \mathrm{C}$. Registrou-se para o mês de agosto a mais baixa amplitude térmica dentre todos os meses do ano. No mês de setembro, último mês do período seco, os valores de temperatura média se apresentaram nas mesmas regiões, contudo diminuíram sua abrangência espacial e aumentaram a média de temperatura que ficaram entre $20,0^{\circ} \mathrm{C}$ e $22,0^{\circ} \mathrm{C}$. Na região Noroeste, onde ocorreram todos os maiores valores de temperatura de Janeira até setembro, os valores registrados foram até $3,0^{\circ} \mathrm{C}$ maiores que o mês anterior, ficando entre $26,0^{\circ} \mathrm{C}$ e $29,0^{\circ} \mathrm{C}$. O mês de Outubro, mês que apresentou a maior média de temperatura entre todos meses do ano, ou seja, foi considerado o mês mais quente no Estado de Goiás e no Distrito Federal, sendo esse o primeiro mês do ano hidrológico, desconfigurou novamente a espacialidade dos valores de temperatura mínima, voltando a ficarem similares aos dos quatro primeiros meses do ano. Aqui podemos observar que os valores de temperatura mínima ocorridos na região Sudoeste do Estado de Goiás estão diretamente relacionados ao período seco. Isso pode ser explicado pelo fato de as massas de ar que atuam na região durante esse período serem munidas de alguma umidade. Os menores valores de temperatura do mês de Outubro se apresentaram nas regiões entre os municípios de Goiânia e Anápolis $\left(20,0^{\circ} \mathrm{C}\right.$ a $\left.22,0^{\circ} \mathrm{C}\right)$ e do Nordeste próxima as fronteiras com a Bahia e Minas Gerais $\left(21,0^{\circ} \mathrm{C}\right.$ a $\left.22,0^{\circ} \mathrm{C}\right)$. Pudemos observar, também, que as maiores médias de temperatura ascenderam para outras espacialidades do Estado de Goiás e Distrito Federal, com destaque novamente para a região Noroeste do Estado de Goiás que apresentou uma vasta área com valores entre $27,0^{\circ} \mathrm{C}$ e $29,0^{\circ} \mathrm{C}$. No mês de novembro os valores de temperatura média mais altos voltam a atenuar-se, de maneira que os maiores valores registrados foram entre $25,0^{\circ} \mathrm{C}$ e $27,0^{\circ} \mathrm{C}$, em média $2,0^{\circ} \mathrm{C}$ a menor que o mês de Outubro, espacializados na região Noroeste do Estado de Goiás. Os valores de temperatura mínima, que no mês de Outubro ocupavam uma pequena porção no Nordeste, se estenderam de Nordeste a Leste e na região entre os municípios de Anápolis e Goiânia $\left(20,0^{\circ} \mathrm{C}\right.$ a $22,0^{\circ} \mathrm{C}$ ). Finalmente, no mês de dezembro, podemos observar praticamente a mesma equidade em relação a espacialização do valores de temperatura máxima e mínima do mês de agosto. Os valores mais altos novamente se apresentaram na região Noroeste do Estado de Goiás, sacramentando essa região como a mais quente do Estado durante todos os meses do ano, com Ano 8 - Vol. 11 - JUL/DEZ 2012 
temperaturas médias entre $25,0^{\circ} \mathrm{C}$ e $27,0^{\circ} \mathrm{C}$. Enquanto os valores de temperatura mínima ocuparam as mesmas regiões do mês de novembro com valores médios compreendendo-se entre $20,0^{\circ} \mathrm{C}$ e $22,0^{\circ} \mathrm{C}$.

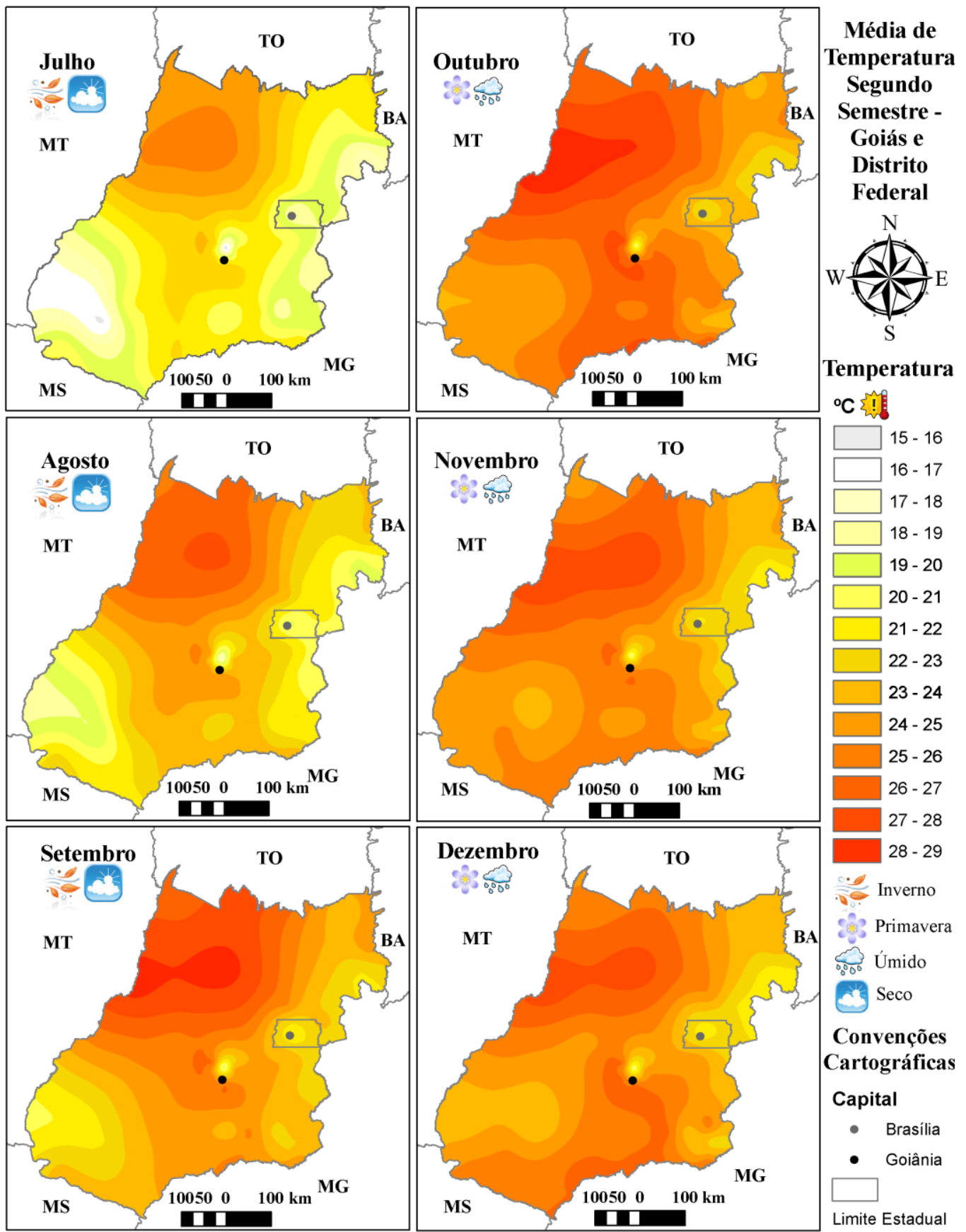

Figura 6. Distribuição espacial da temperatura média no segundo semestre no Estado de Goiás e no Distrito Federal 
Nesse estudo foi estipulada a média de temperatura geral para o Estado de Goiás e o Distrito Federal no valor de $23,4^{\circ} \mathrm{C}$. As maiores médias anuais de temperatura do ar na área de estudos foram encontradas na região noroeste com valores entre $26,0^{\circ} \mathrm{C}$ e $27,0^{\circ} \mathrm{C}$. Enquanto os menores valores foram encontrados, discretamente, na região central, entre Goiânia e Anápolis e ao leste nas imediações de Brasília.

É importante abrir um parêntese para se esclarecer, mais uma vez, sobre a importância de se ter um estudo mais elaborado e detalhado como ao que se propôs o presente trabalho. Em estudos sobre a caracterização geral da temperatura média do ar no Brasil, como os do IBGE, são apresentados, para a área de estudos desse trabalho, apenas duas faixas dessa variável climática (temperatura) para essa região, sendo que quase toda essa área fica compreendida entre as temperaturas médias de $22,0^{\circ} \mathrm{C}$ e $24,0^{\circ} \mathrm{C}$ e, no extremo noroeste, entre $24,0^{\circ} \mathrm{C}$ e $26,0^{\circ} \mathrm{C}$, segundo o referido estudo.

Obviamente, esse parêntese não foi aberto para se criticar o trabalho em questão, que tinha uma proposta de trabalho com escala diferente e, portanto, cumpriu o papel ao que se dispôs. Esse parêntese de cunho comparatório tem o simples objetivo de advertir o quanto é necessário ter estudos mais detalhados desse tipo uma vez, como se pôde observar, a discrepância pode ser muito grande entre os resultados de estudos em escalas diferentes para uma mesma área.

Como podemos observar na Figura 7, a região nordeste apresenta uma grande área com variação da temperatura do ar média entre $26,0^{\circ} \mathrm{C}$ e $27,0^{\circ} \mathrm{C}$, enquanto nas regiões me menor temperatura, já citadas no início do parágrafo, podemos encontrar médias anuais de temperatura do ar que compreendem em até $19,0^{\circ} \mathrm{C}$ e $20,0^{\circ} \mathrm{C}$. Os altos valores de temperatura encontrados na região nordeste da área de estudo, no Estado de Goiás, pode ser explicada por essa ser uma região de menor altitude e com uma extensa planície (Figura 2). Em contraponto, os menores valores de temperatura, entre $19,0^{\circ} \mathrm{C}$ e $22,0^{\circ} \mathrm{C}$, podem ser encontrados nas regiões de maior altitude que são as regiões sudoeste, do entorno de Anápolis, extremo Leste e Sudeste e no Norte, na região da Chapada dos Veadeiros.

É possível dividir a distribuição da temperatura na área de estudos em questão em duas zonas, oeste e leste, onde a temperatura é influenciada por diferentes fatores. No zoneamento oeste pode-se observar que a temperatura segue um padrão de influência latitudinal onde os valores tendem a ser maiores em latitudes baixas (mais próximo ao equador) e menores em latitudes altas (mais próximas aos polos). Sendo assim, é possível observar um aumento gradual da temperatura de sudoeste a noroeste do Estado de Goiás. 
Em contrapartida, no zoneamento leste, a temperatura do ar sofre influência direta das altitudes elevadas encontradas nessa região que se apresentam de sudeste a nordeste. Outro fator determinante nessa discrepância na distribuição espacial da temperatura, entre o oeste o leste, está nas zonas de atuação das massas de ar que atuam sobre esta região. No noroeste atuam principalmente a massa de ar equatorial continental e a massa de ar tropical continental que têm por característica trazer o ar quente. No Sul a maior influência é da massa de ar polar atlântica que tem por característica trazer baixa temperatura dos polos e no leste observa-se a atuação da massa de ar tropical atlântica responsável por trazer o ar com temperaturas elevadas. A massa tropical continental e a massa de ar tropical atlântica que, apesar de ter como característica trazer 0 ar quente sofre influência das grandes altitudes do relevo acidentado das regiões costeiras onde perde calor chegando ao Estado de Goiás e ao Distrito Federal com temperaturas mais amenas.

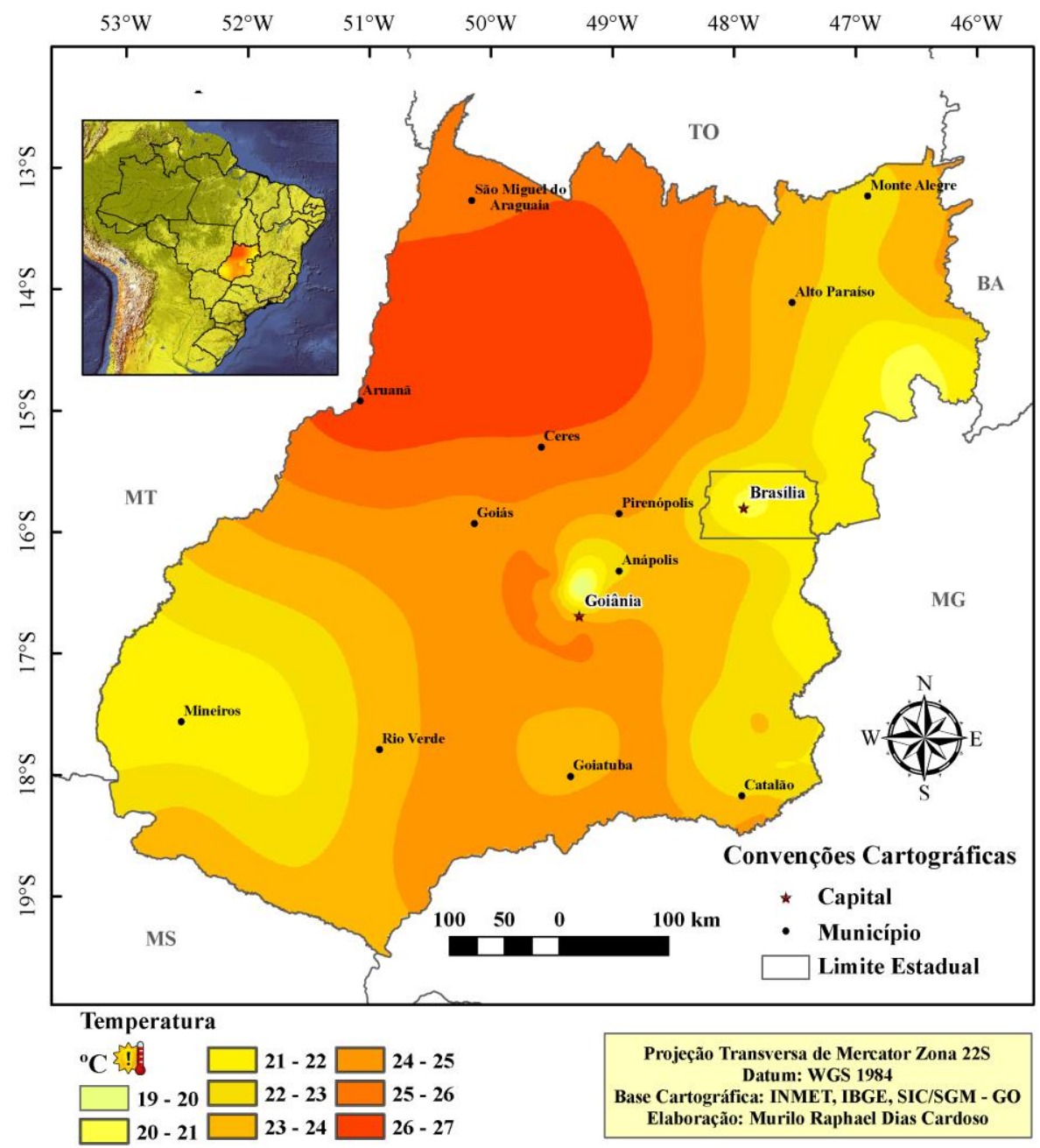

Figura 7. Espacialização da temperatura média anual no Estado de Goiás e no Distrito Federal

Ano 8 - Vol. 11 - JUL/DEZ 2012 


\section{CONSIDERAÇÕES FINAIS}

Em relação a temperatura média mensal no Estado de Goiás e no Distrito Federal, nota-se uma variação térmica de $4,5^{\circ} \mathrm{C}$ entre a média das temperaturas mais amenas, encontradas nos meses de junho e julho, e a maior temperatura, presente no mês de outubro, que é o mês mais quente para essa região. Foi possível perceber que a região mais quente do Estado de Goiás é a Noroeste, enquanto a de temperatura mais amena é uma região localizada entre os municípios de Goiânia e Anápolis.

No que diz respeito aos fatores que corroboram para as variações da temperatura de uma região para outra, nota-se para a escala proposta no trabalho que a altitude tem grande relação a diferença de temperatura na área de estudos ao qual foi realizado esse trabalho, pois na região Noroeste do Estado de Goiás, onde foram encontrados os maiores valores de temperatura é a região de menor altitude da área de estudos, em contrapartida os menores valores médios de temperatura estão relacionados as áreas de maior altitude como o sudoeste do Estado de Goiás e o uma faixa latitudinal que vai do centro ao norte do Estado de Goiás e no Distrito Federal. Em relação ao uso do solo, nota-se que há também uma influência, separando a área de estudos em apenas dois tipos de uso, pecuária e agricultura, notase que na região de clima mais elevado, Noroeste do Estado de Goiás, existe um grande domínio da atividade pecuária, mesmo sendo uma área plana que, no aspecto geomorfológico daria todas as condições para o plantio. Já no Sudoeste do Estado de Goiás onde se encontra temperaturas mais baixas, nota-se uma grande maioria de áreas cobertas pela agricultura, mesmo essa região apresentando uma geomorfologia bastante irregular.

\section{REFERÊNCIAS}

AYOADE, J. O. Introdução a climatologia para os trópicos. 14a ed. Rio de Janeiro. Ed. Bertrand Brasil, 2003.

CORRÊA, R. L.; ROZENDAHL, Z. Apresentando leituras sobre paisagem, tempo e cultura. In: CORRÊA, Roberto Lobato \& ROZENDAHL, Zeny (orgs.). Paisagem, Tempo e Cultura. Rio de Janeiro: Eduerj, 1998. 7-11p.

DA SILVA, F. A. M.; ASSAD, E. D.; EVANGELISTA, B. A. Caracterização Climática do Bioma Cerrado. In: Cerrado: Ecologia e Flora. EMBRAPA Informação Tecnológica, Brasília - DF. 10 Ed. Cap. 3. 69-88p., 2008.

GOMES, P. C. da C. Geografia e Modernidade. Rio de Janeiro: Bertrand, 1996. 368p

IBGE (Instituto Brasileiro de Geografia e Estatística). Ministério do Planejamento, Orçamento e Gestão. Censo 2010 In: [http://www.censo2010.ibge.gov.br]. Acesso em: 21 de outubro de 2011. 
MARCUZZO, F. F. N.; ANDRADE, L. R.; MELO, D. C. R. Métodos de Interpolação Matemática no Mapeamento de Chuvas do Estado do Mato Grosso. Revista Brasileira de Geografia Física, América do Norte, v.4, n.4, p. 696-710, 2011.

NASA (National Aeronautics and Space Administration). Estados Unidos, 2002. Disponível em: <http://www.asterweb.jpl.nasa.gov>. Acesso em: 4 de julho de 2010.

NIMER, E. Climatologia do Brasil. Rio de Janeiro: IBGE, 1989. 422p. 2ed.

PÉDELABORDE, P. Introduction à I'étude Scientifique du Climat. Paris: SEDES, 1970. 246p. 